International Journal of Linguistics, Literature and Translation

ISSN: 2617-0299 (Online); ISSN: 2708-0099 (Print)

DOI: $10.32996 / \mathrm{ijllt}$

Journal Homepage: www.al-kindipublisher.com/index.php/ijltt

\title{
Verbal Extensions and Valency in Limbum
}

\author{
Gratiana Linyor Ndamsah \\ Department of African Languages and Linguistics, University of Yaounde 1, Cameroon
}

$\square$ Corresponding Author: Gratiana Linyor Ndamsah, E-mail: gratiana.ndamsah@yahoo.com

ARTICLE INFORMATION

Received: 16 October 2021

Accepted: 22 November 2021

Published: 15 December 2021

DOI: $10.32996 /$ ijllt.2021.4.12.9

\section{KEYWORDS}

Verbal extensions, valency, aspect, structuralism, suffix

\section{ABSTRACT}

The objective of this paper is to examine the extent to which verbal extensions in Limbum affect valency. Limbum is a Grassfield Bantu language of the Northern group, spoken by the population who occupy a greater part of the Nkambe plateau in DongaMantung Division of the North West Region of Cameroon Binan Bikoi (ed) (2012). To attain my set objective, I carry out an analysis of those affixes (in the case of Limbum, they are suffixes), which are usually attached to verbs and the effect the addition of these suffixes has on the number of arguments in the sentence. Some of these suffixes have a valency decreasing effect, while some have a valency increasing effect on the verbs. The orientation of the discussions here centres on the description of the morpho-syntactic structure of the Limbum verb. In this regard, the analysis herein draws inspiration from the theory of Valency as proposed by Tesnière in 1959 and his followers and the Structuralist Framework as propounded by De Saussure and his disciples who hold that linguistic unit: words, phrases and sentences are perceived as a concatenation of smaller units which hold a close relationship between them. The structure of the Limbum sentence containing verbal extensions that express aspectual meanings have three consequences on the number of arguments that the verb takes: the discussions here show that, while the morphemes $-\mathbf{r i}, \mathbf{- \Sigma i}$, and $\mathbf{- s e}$ marking the attenuative, the pluractional, and the distributive aspects respectively have no effect on the number of arguments taken by the verb to which they are suffixed, the causative morpheme -si, has a valency increasing effect on the verb to which it is affixed. In the same light, the reciprocative - $\mathbf{n i}$, the separative -ti and the iterative - Nger, when suffixed to a verb, have the tendency of increasing the number of arguments that the verb takes. In a bid to clarify the structural cartography of verbal extensions in Limbum, the last part of this paper is dedicated to a presentation of some suffixes like -ri and si, which has, with the evolution of the language, fossilized with the verb root to the extent that they have become an integral part of the verb in a way that they cannot be detached from each other. Conclusively, the paper shows that verbal extensions in Limbum are, for the most part, suffixal morphemes. While some of these suffixes have no effect on the number of arguments the verb subcategorizes for, some have a valency decreasing effect on the verb while others, on the other hand, have a valency increasing effect. Others have outrightly merged with the verb root.

\section{Introduction}

Valency is an important area of the description of a language. In the literature, different models have proposed a varied number of word classes to which the property of valency is ascribed. These range from the verb, the noun, adjectives, prepositions to adverbs (Hhuddleston and Pullum 2002, Herbst and Schuller 2008). That notwithstanding, the theory that underlies the discussions here is the Theory of Valency as discussed in Faulhaber (2011). In this theory, the verb is considered as the most central element of the sentence and the main determinant of its structure. In this regard, the analysis here will consider the verb as the valency carrier in that it is that element that determines the number of arguments that it takes.

Copyright: (c) 2021 the Author(s). This article is an open access article distributed under the terms and conditions of the Creative Commons Attribution (CC-BY) 4.0 license (https://creativecommons.org/licenses/by/4.0/). Published by Al-Kindi Centre for Research and Development, London, United Kingdom. 
In the following paragraphs, I explore the notion of valency in relation to the verb as it obtains in Limbum, a Grassfield Bantu language of the Northern group, Binam Bikoi (ed) (2012). Valency as used here refers to the number and type of bonds that a syntactic element may take or form with another. In this paper, valency refers to the type of bond that the verb forms with its arguments. I refer to subjects of sentences and verbal complements in my arguments here. In Limbum, when certain morphemes are affixed to the verb, they affect the valency originally attributed to the verb. Some of these affixes (in the case of Limbum, they are all suffixes) increase the number of arguments attributed to the verb, others have a decreasing effect on the number of arguments the verb would normally take, and yet others do not have any influence on the number of expressions assigned to the verb. It is, therefore, my aim in this paper to identify the various verbal extensions in Limbum and group them with regards to the impact they have on the number of arguments attributed to the verb as a result of the addition of these extensions.

This paper is divided into seven (7) sections, with the first and the last sections being the introduction and the conclusion respectively. Section two (2) presents the theoretical frameworks that guide the analysis of the data. In section three (3), I present the structure of the Limbum sentence using the verbs that could potentially be open to the attribution of an affix. Section four (4) focuses on a discussion of suffixes that affect the valency of the verb. In section five (5), given that not all verbal extensions in Limbum affect the valency of the verb to which they are attached, I handle those verbal extensions that do not alter the number of arguments the verb has subcategorized for. In the sixth (6) section, in order to understand the Limbum data in its entirety, I present those extensions that, due to the evolution of the language, have been glued to the verbs in such a way that they are inseparable. If they are separated, no meaning can be ascribed to the verb root.

\section{Theoretical orientation}

The analysis in this paper is based on an eclectic approach: it uses the Theory of Valency as inspired by Tesnière (1959), Hollein (2020) and the Structuralist framework as put forth by Saussure and his followers.

The Theory of Valency holds that this: "...is a grammatical theory which focuses on the verb as its canter. ...on the idea that verbs structure sentences by binding specific elements as atoms do." Hollein (2020:1). According to the Valency Theory, the verb is the valency carrier and it determines and creates a tight bond with its complements (complements here include subjects). Any other addable elements to the structure of the sentence are not determined by the verb. These include adjuncts. Because the verb is the valency carrier in language, the use of the assumptions of this theory justifies the discussion of the effects of the affixation of other morphemes to the verb to the structure of the sentence.

As stated earlier, I also use ideas of language put forth by Ferdinand de Saussure and his followers (Structuralism). Some of the tenets of this theory hold that language is a system and, as such, must be studied by its structure. As a system, every individual word is meaningless outside the confines of that structure. Hence every element in this system should be studied in its context of use. Therefore, in the present paper, I examine how, due to the addition of certain affixes to the verb, the structure of the construction may/may not be affected.

\section{The structure of the Limbum sentence}

In the following paragraphs, I present the structure of the Limbum sentence. In most of the cases, I will be using the verbs that can take extensions so that the presentations in subsequent sections will be rendered more visible.

\subsection{Avalent constructions}

An avalent verb refers to a verb or verb phrase whose valency is null. In other words, the verb or verb phrase does not subcategorize for any argument (agent). These are often said to be impersonal. In Limbum, there are no verbs that are impersonal. Considering the English sentence in (1) below,

\section{It is raining}

At first sight, one might be tempted to analyze the pronoun "it" as being the subject of the construction. This will not be correct because this pronoun, otherwise referred to as an impersonal pronoun, does not have an antecedent. While in the English language, avalent verbs like "rain" exists, this is not the case in Limbum. Take the construction in (1) above in Limbum; obligatorily, there must be a subject. The construction in (2) below is illustrative.

2. mbèn $t \int \mathrm{e}^{-}$gwè
rain Prog. faill
"it is raining"

There is no way in this language that one can use a verb without either a phonetically realized or an implied subject except in the imperative. 
Expressions in Limbum like those in (3a) and (b) below, though do not contain overt subjects, translate understood subjects. Let us consider them.
3a. nàti
"get up (2PSg)"
b. nàti-ni
"get up|up $(2 \mathrm{PP} 1) "$

The constructions in (3a) and (b) above look like what can be described as avalent verbs. But this is not true, given the fact that these are in the imperative form. The only difference between the two constructions is that while the command in ( $3 \mathrm{a}$ ) is addressed to a second person singular subject, that in (b) is addressed to a second person plural subject.

\subsection{Monovalent constructions}

In human language, there are certain verbs that do not subcategorize for a direct object by their very nature. This type of verb has been described in the literature as monovalent (a verb that subcategorizes for an agent subject that can be morphologically expressed or null but understood). In Limbum, some verbs are inherently monovalent in the sense that they subcategorize only for one argument, which is the agent of the action expressed by the verb. The examples below illustrate this fact.

$\begin{array}{llll}\text { 4a. mè sù } & \text { émbē pkū: } \\ \text { I descenld from } & \text { bed }\end{array}$

"I have come down from the bed"

b. ţ⿸厃㔾 t tra à kwē

tree this SM die

"This tree is dead"

The verbs su $\exists \exists$ : "descend" and kwe\#" "die" by their very nature and meaning, subcategorize for a subject. The verbs can, however, take adjuncts, as is evident in the construction in (4a). Verbs like the ones in (4a) and (b) are said to be monovalent.

\subsection{Bivalent constructions}

Talking about bivalent verbs, I refer to verbs which, by their inherent properties, cannot function in construction without a subject and a direct object. This class of verbs is traditionally known as mono-transitive verbs. Some examples of these verbs are used in the constructions below.

\section{5a. Njuh t $\int \bar{e}$ yē byē: \\ Niuh Prog. eat food \\ "Njuh is eating"}

$\begin{array}{ccc}\text { b. } & \text { m̀ k̀̀ } & \text { wè } \\ \text { I like you } & \text { "I like you" }\end{array}$

In the above sentences, the action expressed by the verb obligatorily, must be transmitted to a patient object. Unlike in languages like English, where an expression like I am eating is grammatical, in Limbum any attempt at removing the direct object renders the construction ungrammatical if the construction is uttered as a response to a question. For example, if one is asked: what are you doing with the food? The response: I am eating is acceptable as far as the English language is concerned. Contrarily, removing bye\#: "food" and $w E \exists$ "you" from the constructions in (5a) and (b) renders the expressions senseless, except it is used in a specific context. In other words, within a specific discourse frame, the constructions as in (6a) and (b) below can be acceptable as situational sentences.

$\begin{array}{cccc}\text { 6a. } & \text { ?Njuh } & \text { t5e } & \text { yē } \\ \text { Njuh } & \text { Prog } & \text { eat } \\ \text { b. ?m̀ } & \text { kòn } & \\ \text { I } & \text { like } & \end{array}$

N.B. The question mark preceding the above constructions indicate that these sentences can be acceptable. 


\subsection{Trivalent constructions}

Trivalent constructions refer to those constructions in which there is a verb that requires three arguments that are either phonetically represented or implied: an agent - subject, a patient - object and a theme/beneficiary - object. Examples of constructions with these verbs are given below.

\section{7a. Mallah tsè fà ywà? nè Njuh Mallah Prog give book Prep. Njuh "Mallah is giving a book to Njuh."}

\section{b. Njuh tsē nònsē ywà? mbé pku: Njuh Prog. put book Prep. bed "Njuh is putting the book on the bed"}

The subcategorization frame of the verbs fa $\square \square$ "give" and $n \square \Uparrow$ Nse\#f "put" demands that in construction, these verbs should form a bond with an agent subject, a patient object and a beneficiary indirect object for fa $\square \square$ and a location indirect object for $\mathrm{n} \square \Uparrow$ Nse\#. These kinds of verbs are traditionally referred to as di-transitive verbs.

Other patterns of sentences that are found in Limbum result from the addition of adjuncts, or they are complex constructions or derived through movement in the syntax. Limbum is essentially an S.V.O. language.

\section{Valency affecting verbal extensions}

The notion of verbal extensions has been given varied definitions by different authors (Katamba 1993, Mutaka and Tamanji 2000) cited by Kanga (2007) and others. Nonetheless, most if not all of them are unanimous that this concept falls within the domain of verbal morphology. Mutaka and Tamanji (2000) consider verbal extensions as suffixes that are added to the verb root to create a new verb stem, Matsimbe 1994) also considers verbal extensions as bound morphemes hosted by the verb root. However, these authors differ as to whether verbal extensions fall under derivational or inflectional morphology. While Mutaka and Tamanji place this concept under derivational morphology, Matsimbe considers verbal extensions as inflexional morphemes. Given the Limbum data, the discussions in this paper do not enter this debate, but rather analyses bound forms in Limbum, which are added to the end of verbs and their effect on the structure of the constituent parts of the sentence.

As stated earlier, the sentence pattern, in terms of the number of arguments a verb subcategorizes for, might change when the said verb receives an affix. Some affixes do not affect the valency of the verb while some extensions influence the number of arguments of the sentence. In the following paragraphs, I undertake a discussion of those affixes which affect the verbal valency by increasing the number of arguments and those that contrarily decrease the number of arguments.

\subsection{Valency increasing extensions}

The Limbum data has revealed only one extension that affects the valency of the verb. The extension that has the tendency of increasing the number of arguments which the verb subcategorizes is the suffix $-\mathrm{si} \Leftrightarrow$. Discussions on the functioning of this morpheme in relation to verb valence are carried out in the paragraph below.

\subsection{1. causative -si $\Leftrightarrow$}

When the morpheme -si $\Leftrightarrow$ is suffixed to a verb that is intransitive by its very nature, it automatically subcategorizes for a following direct object. Let us examine sentences (4a) and (b), repeated here as (8a) and (b).

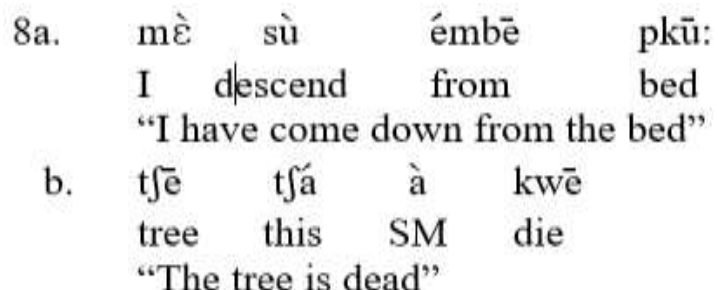

There is no direct object in both (8a) and (b) above. The valence of the verbs in the constructions is one. But when the suffix -si is added to the above verbs, the verbs obligatorily sub-categorize for a following direct object. This is shown in the sentences below. 


$\begin{array}{ccccc}\text { 9a. mè } & \text { sù - sì } & \text { ntā? émbē pkū: } \\ \text { I } & \text { descend-Caus chair from bed }\end{array}$

"I brought down the chair from the bed"

"I caused the chair to come down from the bed"

b. mè kwé-sì $\mid$ t $\int \bar{e} \quad$ t $\int a ́$

I die - Caus tree this

"I have caused this tree to die"

A comparison of the sentences in ( $8 a$ ) and (b) above with their corresponding causative counterparts in (9a) and (b) reveal that this suffix causes an increase in the number of arguments: the intransitive verbs have now become transitive because of the suffixation of the morpheme -si. This is the reason for the ungrammaticality of the constructions in (10) below.

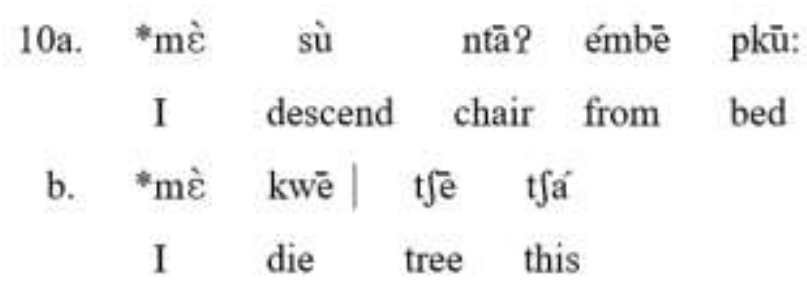

N.B. the presence of the asterisk indicates ungrammaticality.

As can be seen, the ungrammaticality of the above constructions is because the verbs without the causative suffix cannot take a direct object. In other words, these verbs can only become transitive if they are put in the causative form. In this regard, I have referred to this extension as a valency increasing extension.

\subsection{Valency decreasing extensions}

A number of extensions in Limbum have the capacity to cause the number of arguments subcategorized by the verb to decrease. These extensions include the reciprocative $-\mathrm{ni} \Leftrightarrow$, the separative $-\mathrm{ti} \Leftrightarrow \Leftrightarrow$, and the iterative $-\mathrm{Nge} \cong \simeq$ r. Discussions of each of these are carried out in the following paragraphs.

\subsubsection{Reciprocative $-n i \Leftrightarrow$}

When one talks of reciprocity, one refers to a relation of mutual dependence, action or influence. This, in Limbum is expressed by the suffixation of the morpheme $-n i \Leftrightarrow$ to the verb root.

I discuss the influence of this morpheme on the structure of the sentence regarding valency using the following examples.

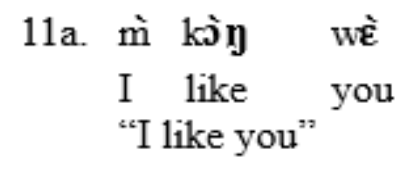

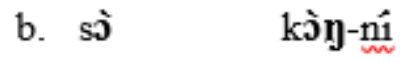

we. like-Recipr.

"we like/love each other"

12a. ì bà Nfor

I hate Nfor

"I hate Nfor"

b. wèr bà-ní|

we hate- Recipr.

"we hate each other" 
In (11a) and (12a) above, the verbs $k \square \exists N^{\prime \prime}$ like" and $b a ̀$ "hate" are void of any affix. In this state, the verbs are obligatorily transitive and take two arguments: an agent subject and a theme object. When the morpheme $-n i \Leftrightarrow$ is suffixed to the verbs, as can be seen in (11b) and (12b), the direct objects disappear. A construction in Limbum with the verbs $k \square \exists N$ and bà without direct objects is ruled out as ungrammatical, except they are uttered within a specific discourse frame. In the same light, if the direct object is inserted when the reciprocal marker is suffixed to the verb roots $k \square \exists N$ and $b a$, the resulting constructions are considered as illformed. These facts are illustrated below.

\section{3a. ?m̀̀ kìn}

I like

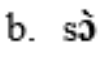
kòn-ní wè we-exc1. like- Recipr. you

14a. ?m̀̀ bà

I hate

b. *wèr bà-ní

Nfor

we hate-Recipr. Nfor

While (13a) and (14a) may be acceptable in Limbum in the case of a specific discourse situation in that the utterances point to the fact that there is an implied or understood object, (13b) and (14b) are ruled out completely as ungrammatical.

4.2.2. Separative $-t i \Leftrightarrow$

When the morpheme $-t i \Leftrightarrow$ is suffixed to a group of verbs, the verb expresses the separative aspect. This means the patient of the action expressed by the verb denotes an activity that expresses the notion of putting apart. The addition of this morpheme also renders divalent verbs to become monovalent. The sentences below are demonstrative.

15a. mu: à kép ntā?

Child SM break chair

"the child broke the chair"

b. ntāi à kép - tî̉

chair SM break-Sepr.

"the chair is broken"

16a. mu: à sà: tjè?

Child SM tear clothe

"the child has torn the clothe"

b. tfè? à sà:- tî

clothe SM tear-Sepr.

"the clothe is torn"

In the constructions in (b) above, the objects of the verbs $k e \Leftrightarrow p$ and $s a \exists$. which are nta $\#$ ? and $t \Sigma E \exists$ ? respectively no longer appear in post-verbal position. They all appear as the syntactic subjects of the corresponding sentences. Hence the number of arguments in the constructions in (b) are reduced to one as a result of the suffixation of $-t i \Leftrightarrow$ as opposed to the two arguments in the (a) sentences. In other words, while the constructions in (a) have agent subjects, those in (b) are agentless. 


\subsubsection{Iterative - $N g e \cong r$}

To some verbs, the suffix $\cong-N g e \cong r$ can be added to express the action of repetition. Most of the verbs to which this iterative morpheme can be added are monovalent verbs. But when the suffix -Nger is affixed to the verbs, they become bivalent. The following constructions illustrate this.

17a. wowè á yē byē

They SM eat food

"they have eaten"

b. wōwè á yē-ngér

they SM eat-Iter

"They have eaten (many times)"

18a. bō bājrò á nō mrù?

children male SM drink wine

"the boys have drunk wine"

b. bō bāyrò á nō-ngér

children male SM drin-Iter.

"the boys have drunk"

The verbs in sentences (17a) and (18a) have a valency of two (2): a subject and a direct object. With the suffixation of the iterative morpheme - Nge $=r$, the valency changes. It can be noticed from the sentences in (b) above that with the presence of the iterative aspectual morpheme, the valency of the verbs become one (1): the subject only. This points to the fact that the iterative morpheme $\simeq-N g e \cong r$ in Limbum is a valency decreasing extension.

\section{Extensions with no effect on valency}

As noted in an earlier section, not all verbal extensions in Limbum have an incidence on the number of arguments that the verb takes. There are some verbal extensions which when affixed to the verb, do not change the number of arguments that the verb subcategorizes for. In this section, I discuss these verbal extensions and show that their presence has no effect on the valency of the verb to which they are attached.

\subsection{Attenuative $\exists-r i \Leftarrow$}

When the morpheme $-r i \Leftarrow$ is suffixed to a verb, the meaning changes in the sense that the action or state expressed by the verb is considered reduced or lessened. This morpheme is often affixed only to verbs that have to do with colour. I present examples of sentences with verbs void of this morpheme and those which contain it in the examples that follow.

19a. bt $\int \grave{\varepsilon} ?$ tfá ví $\overrightarrow{\mathrm{s}}$

\section{clothes these they black}

\section{"these clothes are black"}




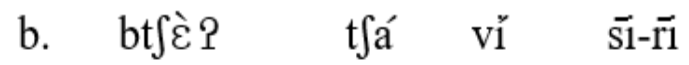

clothes these they black-Att.

"these clothes are blackish"

20a. m̄ggòmbé ptfá vỉ bàn

plantains these they red

"these plantains are red/ripe"

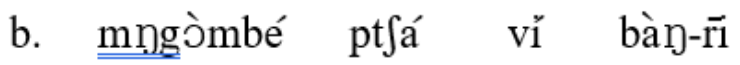

plantains these they red-Att.

"these plantains are almost ripe"

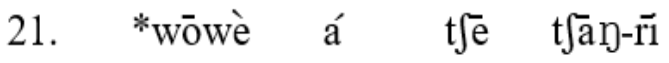

They SM Prog run-Att.

This suffix is affixed only to adjectival verbs. Other verbs cannot take this suffix, as shown by

the ungrammaticality of (21) above. $t \Sigma a \Leftarrow N$ is an action verb while $b a \exists N$ "red" and si\#" black" are adjectival forms that are used as verbs. One of the tests that show that $b a \exists N$ and si\# as used in the constructions above are actually verbs is the fact that they can be used with all the verbal modalities of tense, aspect and mood as the sentence in (22) below shows.

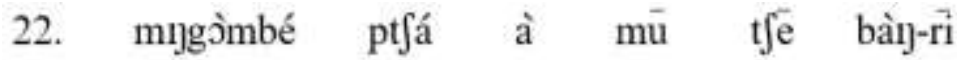

Pantains these SM P3 Prog. Red-Att.

"these plantains were reddish (almost ripe)"

Notice the presence of $m u$ which is a tense morpheme and $t \Sigma e \Leftarrow$, the progressive aspectual morpheme. By their very meaning, they are adjectives, but they are used here as verbs. Therefore, I refer to these forms as adjectival verbs.

\subsection{Pluractional $-\Sigma i \Leftarrow$}

In Limbum, when the morpheme $-\int i \Leftarrow$ is added to a verb, it denotes the fact that the action of the verb is done repeatedly. The presence of this extension does not have an incidence on the number of arguments the verb takes. The sentences in (23a), (24a) and (25a) illustrate cases where the verbs are used, void of this suffix, while their corresponding (b) sentences show the use of the suffix.

23a. 1]kt́ t té tù Nfor gòr

Chief Prog. send Nfor much

"the chief is sending Nfor much"

b. நkú t tse tū- $\sqrt{1} \quad$ Nfot

Chief Prog. send-Plur Nfor much

"the chief is frequently sending Nfor (many times)" 
24a. mū: tكè mù? rkìn

Child Prog. open pot

"the child is opening the pot"

b. mū: t $\sqrt{\mathrm{e}}$ mù? $-\sqrt{\frac{1}{1}}$ rkìn

Child Prog. open-Plur. pot

"the child is opening the pot (many times)"

25a. Nfor t tse kepp tfít fï

Nfor Prog. Break stick

"Nfor is breaking a stick"

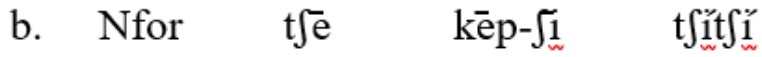

Nfor Prog. break-Plur. Stick

"Nfor is breaking a stick (into small pieces)"

All the verbs in the above examples subcategorize for two arguments: an agent subject and a patient object, as shown by the constructions in (a) above. In the sentences in (b), the suffix - $\Sigma i$ has been added to the verbs, but the valency remains two (2). Hence the $-\Sigma i \square$ extension does not affect the valency of the verb to which it is affixed.

This aspect is also attested in some other Grassfield Bantu languages like the Kom language (a Grassfield Bantu Language of the Ring group). In this language, the pluractional marker is the morpheme $-l \rightarrow \Leftrightarrow$. The following examples taken from Mba and Chiatoh (2003) are illustrative.

25a. nyím "smile"

b. Nyím-lf́ "smile several times"

26a. lúm "bite"

b. lúm $1 f$ "bite several times

adapted from Mba and Chiatoh (2003)

\subsection{Distributive $-\mathrm{se} \Leftrightarrow$}

When the morpheme -se $\Leftrightarrow$ is affixed to verbs, the verb's meaning denotes an action carried out by several people separately or by several persons individually. Just like the iterative $-N g e \Leftrightarrow r$, this suffix has the peculiarity that it is affixed only to monosyllabic verbs and never to verbs of any other syllable type. We illustrate its use with the examples in (27) and (28) below.

27a mī: à byè? ví bbà wé

Child SM carry Poss. bags already

"The child has already carried his bags." 


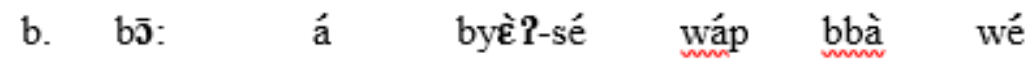

Children SM carry-Distr. Poss. bags alread

"The children have already carried their bags."

28 a. mbvī ý̀ níy mbé நká?

goat SM enter Prep. fence

"The goat has entered the fence."

b. mbvī vì níy-sé mbé jká?

goats SM enter-Distr. Prep. fence

"All the goats have entered the fence."

Comparing the sentences in (a) above with their corresponding ones in (b), one notices that all the subjects in (b) are in the plural form. This is because the suffix -se $\Leftrightarrow$ subcategorizes only for subjects that are plural given the fact that the actions described by the verbs after the addition of -se $\Leftrightarrow$ are carried out by many people, though separately. In other words, it is understood that there are many persons or entities involved in the action and either all of them are performing the action separately at the same time or it is performed one after the other. A construction like that in (29) below is ruled out as ungrammatical if it must be given a distributive reading. However, if the interpretation is that the children joined hands to carry a bag belonging to them, then the construction can be accepted, but if we have to express the distributive, -se $\Leftrightarrow$ must be affixed to byE $\exists$ ? since the subject of the sentence is in the plural form. Following the same line of thought, the construction in (29b) is only accepted in Limbum if the goats are considered as a single whole. In this case, the focus is placed on the fact that each goat walked into the house.

29a. b̄̄: á byè? wáp bbà wé

Children SM carry Poss. bags already

"The children have already carried their bags."

b. mbvī ví nín mbé Đká?

goat SM enter Prep. fence

"The goat has entered the fence."

\section{Fossilized verbal extensions}

In the language under study, there are some verbs that show evidence of the presence of extensions. The problem with this class of verbs is that it is difficult to separate the extensions from the verb roots. This is because if this is done, the part that remains cannot stand as a word. This conclusion is arrived at in the case where a word is considered as the smallest unit of language that is associated with a particular meaning and can be expressed by itself. In this regard, a word is a sound-meaning unit of a language. Hence the fact that these extensions have the same phonetic shape as the ones treated earlier and they are inseparable from the 'root'; I analyze the relationship between these roots and their extensions as a fossilized one. Most probably, during the evolution of the language, these extensions have been fussed with the root to the extent that both are bound to each other. What I discuss here can be better understood by considering the discussions in the following sections.

\section{1. the morpheme -ri $\Leftrightarrow$}

The morpheme -ri, as used here, has no meaning attached to it. This morpheme has fossilized with the root to the extent that with the root verb, they have become inseparable. The constructions in (30) that follow will better explain this fact. 


30a. lòr à bïgri
Stone SM roll
"the stone rolled"
b. *mè bìn lòr
I ? stone

The construction in (30b) is considered meaningless because an integral part of the verb, -ri has been dropped. Note should be taken here that -ri as used here is different from the attenuative -ri discussed in section 4.2.1. above. In the former treatment of $r i$ (attenuative), while this morpheme can be detached from the verb and the verb will be meaningful, the fossilized cannot be treated the same way.

\subsection{The morpheme $-\mathrm{si} \cong$}

The morpheme $-s i \Leftrightarrow$ occurring with certain verbs has fossilized to the extent that they have become inseparable. Any attempt at separating them renders the separate parts meaningless. The sentences below are illustrative.

$\begin{array}{cccc}\text { 31a. Mallah } & \text { à } & \text { kènsì } & \text { Đgūp } \\ \text { Mallah } & \text { SM } & \text { carefully control } & \text { fowl } \\ & & \text { movement }\end{array}$

"Mallah has carefully controlled the owl"

b. Mallah t $\overline{\mathrm{e}}$ sịnsi ntā?
Mallah Prog. Wipe chair
"Mallah is wiping a chair"

N.B. 'carefully control movement' is used here for lack of a better way of expressing the action of this verb.

At first sight, one would have the impression that the morpheme -si $\Leftrightarrow$ as used in thirty (31) above is the same as that used to mark the causative as discussed in section 4.1.1. The difference between causative -si $\Leftrightarrow$ and the $-s i \Leftrightarrow$ discussed here is that the former has not yet fossilized with the verb as such can be separated from the verb and the verb will still translate an idea while with the latter if the two parts are separated, none of the parts will be associated with any meaning. The ungrammaticality of the constructions in (32) below is because of the deletion of this morpheme.

\begin{tabular}{|c|c|c|c|c|}
\hline 32a. & *Mallah & à & kèn & ฤgēp \\
\hline & Mallah & SM & $?$ & fowl \\
\hline b. & *Mallah & $t \sqrt{\mathrm{e}}$ & $\sin$ & ntā? \\
\hline & Mallah & Prog. & $?$ & chair \\
\hline
\end{tabular}

Since $-s \Leftrightarrow i$ in the cases above has become an integral part of the verb, it can only be used together, bound to the verb root. Causative $-s i \Leftrightarrow$ and fossilized $-s i \Leftrightarrow$ are simply homophones.

\section{Conclusion}

The main objective of this paper was to examine the Limbum data to show the effect of verbal extensions on the structure of the sentence with regards to the number of arguments the verb subcategorizes for. The discussions here have shown that only the causative morpheme $s i \Leftrightarrow$ reduces the valency of the verb to which it is affixed. As far as the extensions that increase the verbal valency are concerned, the reciprocative $-n i \Leftrightarrow$, the separative $-t i \Leftrightarrow$ and the iterative $-N g e \Leftrightarrow \exists$ were identified as having this effect on the verb. It was also demonstrated that some verbal extensions do not affect the valency of the verb to which they are affixed. These include: the attenuative $-r i \Leftarrow$ the pluractional $-\Sigma i \square$ and the distributive $-s e \Leftrightarrow$. In the analysis of fossilized verbal extensions, it was shown that there are two morphemes in Limbum which have fused with the verb root: $-r i \Leftrightarrow$ and $-s i \Leftrightarrow$. 
Funding: This research received no external funding.

Conflict of interests: The authors declare no conflict of interests.

Abbreviations:

$\begin{array}{ll}\text { Prog. - Progressive } & \text { Prep. - Preposition } \\ \text { 2PSg - Second Person Singular } & \text { Caus. - Causative } \\ \text { 2PPI. - Second Person Plural } & \\ \text { SM - Subject Marker } & \text { Att. - Attenuative } \\ \text { Distr. - Distributive } & \text { Plur. - Pluractional } \\ \text { Recipr -- Reciprocative } & \text { Poss. - Possessive }\end{array}$

Sepr. - Separative

Iter. - Iterative

\section{References}

[1] BINAM B. C. (2012) Cartographie Administrative des langues du Cameroun : Administrative atlas of Cameroun (AAC). CERDOTOLA, Yaoundé

[2] FAULHABER, S., (2011). Verb Patterns: A Challenge for Semantics-Based Account. De Gruter, Berlin

[3] HERBST, T. and Schulter, S. (2008). An Introduction to Syntactic Analysis: A Valency Approach. Gunter Narr Verlag: Tubingen

[4] HOLLEIN, D., (2020). Valency Theory 06 April 2021 www.oxfordbibliographies.com

[5] HUDDLESTON, R. D. and Geoffrey K. P. (2002). The Cambridge Grammar of the English Language. Cambridge University Press, Cambridge, UK

[6] KANGA, D., (2007). Verbal Extensions in Changana: A Re-statement in Akindele et al. (eds) 2007 LASU Journal of the Linguistics Association of South African Development Community (SADC) Universities. Linguistics Association of SADC Universities. Vol. 3 pp 51-60.

[7] KATAMBA, F., (1993). Morphology. Modern Linguistics series. Houndsmill and London: Macmillam Press.

[8] MATSIMBE, S. F., (1994). The Status of Verbal Affixes in Bantu Languages with special reference to Tsonga: Problems and Possibilities in South African Journal of African Languages. Vol. 14 No 4:163-176

[9] MBA, G. and B. CHIATOH, (2003). Verbal Extensions in Kom" in DIATA, D. F. and G. MBA (eds) Studies of Voice through Verbal Extensions In Nine Bantu Languages spoken in Cameroon, Gabon, DRC, and Rwanda. Lincom Europa: munich.

[10] MUTAKA, N. M., and P. N. TAMANJI (2000). An Introduction to African Linguistics. Lincom handbooks in Linguistics. Munich: Lincom Europa. Vol. 6. 